$\begin{array}{ll} & \text { Etnográfica } \\ \text { etnográfica } & \text { Revista do Centro em Rede de Investigação em }\end{array}$

Antropologia

vol. $24(2) \mid 2020$

Vol. $24(2)$

\title{
"Nosotros estábamos acá antes": pluralizando la historia a partir del mito de origen de los guaraníes en Jujuy (Argentina)
}

"We were here before": Pluralizing history from the myth of origin of the Guarani in Jujuy (Argentina)

\section{Sonia Elizabeth Sarra}

\section{OpenEdition}

Journals

\section{Edición electrónica}

URL: https://journals.openedition.org/etnografica/9047

DOI: 10.4000/etnografica.9047

ISSN: 2182-2891

\section{Editor}

Centro em Rede de Investigação em Antropologia

Edición impresa

Fecha de publicación: 1 junio 2020

Paginación: 465-484

ISSN: 0873-6561

\section{Referencia electrónica}

Sonia Elizabeth Sarra, «"Nosotros estábamos acá antes": pluralizando la historia a partir del mito de origen de los guaraníes en Jujuy (Argentina)», Etnográfica [En línea], vol. 24 (2) | 2020, Publicado el 31 julio 2020, consultado el 19 enero 2022. URL: http://journals.openedition.org/etnografica/9047 ; DOI: https://doi.org/10.4000/etnografica.9047

\section{(c) (7) \&}

Etnográfica is licensed under a Creative Commons Attribution-NonCommercial 4.0 International License. 


\section{“Nosotros estábamos acá antes": pluralizando la historia a partir del mito de origen de los guaraníes en Jujuy (Argentina)}

\section{Sonia Elizabeth Sarra}

Tomando como punto de partida versiones del ampliamente difundido mito de los mellizos registradas entre los guaraníes de Calilegua (Jujuy, Argentina), me propongo analizar sus implicancias histórico-políticas a la luz de algunos de los aportes del giro ontológico. El relato de los mellizos les permite a los guaraníes con quienes trabajo reflexionar sobre su origen y pensarse en la historia como pueblo ancestral que en tiempos míticos se expandió por el continente americano. Lejos de una abstracción, este mito implica un posicionamiento histórico y político frente a los discursos que estigmatizan a los guaraníes de Jujuy como "extranjeros" y ponen en tela de juicio su ancestralidad en el territorio. Tomar en serio la mitología indígena conduce ya no a determinar la verdad o falsedad de ciertos relatos e historias nativos o la coincidencia o no con la historiografía, sino que apunta al proyecto político de pluralizar la historia.

PALABRAS CLAVE: mito, historia, guaraníes, Jujuy, giro ontológico.

"We were here before": Pluralizing history from the myth of origin of the Guarani in Jujuy (Argentina) - Taking as a starting point versions of the widely renowned myth of the twins registered among Guarani people of Calilegua (Jujuy, Argentina), I intend to analyze its historical and political implications in the light of some of the contributions of the ontological turn. The tale of the twins allows the Guarani with whom I work to reflect about their origin and think themselves in the history as an ancestral nation which expanded across the American continent in mythical time. Far from an abstraction, this myth of origin involves a historical and political position against those discourses that stigmatize Guarani of Jujuy as "foreigners" and bring their ancestrality in the territory into question. Instead of questioning the truth about these other histories or claiming historiographical coincidence, taking native indigenous myths seriously leads to the political project of pluralizing history.

KEYWORDS: myth, history, Guaraníes, Jujuy, ontological turn.

SARRA, Sonia Elizabeth (soniaelisarra@gmail.com) - Centro de Investigaciones en Ciencias Sociales Regional, Conicet, Argentina. 


\section{INTRODUCCIÓN}

Este texto se basa en el trabajo etnográfico realizado con guaraníes del Noroeste Argentino (NOA), en su mayoría pertenecientes a la comunidad Kuape Yayemboat⿱亠 (Calilegua, Dpto. de Ledesma, Jujuy), entre los años 2015 y 2019. ${ }^{1}$ Mbaporenda, según las traducciones "lugar donde se produce" o "lugar donde hay trabajo", identificada con Argentina y puntualmente con los ingenios azucareros del NOA, es vista por los propios guaraníes como un contexto "aculturado" ${ }^{2}$ en comparación con la región guaraní del país vecino de Bolivia. Las comunidades guaraníes de Jujuy se alejan del ideal de "pureza" asociado al aislamiento y la distancia que muchas veces se privilegió en nuestra disciplina. Rodeadas de mares de cañaverales e impregnadas de contaminante olor a bagazo, ${ }^{3}$ estas comunidades periurbanas y sin tierra tienen intenso contacto con la empresa Ledesma S.A.A.I., ${ }^{4}$ con la sociedad envolvente, con otros grupos étnicos y con otredades y materialidades del más amplio espectro. Fue en este contexto que me contaron el mito de origen y expansión continental de los guaraníes por el accionar de gemelos míticos en el que se centra este trabajo.

La categoría "mito", por su connotación negativa en tanto, desde el sentido común, sinónimo de "historia falsa", ocupa un lugar privilegiado en las "equivocaciones sin control" (Castro 2004; Blaser 2009) y en las traducciones que traicionan más la fuente original que el aparato conceptual propio. En una oportunidad, un guaraní nos contaba a mí y a un locutor de una radio local, ambos karai ${ }^{5}$ leyendas sobre cientos de guaraníes que vinieron a Mbaporenda ("Argentina") escapando de la Guerra del Chaco entre Paraguay y Bolivia (1932-1936). Para ocultarse y no ser reclutados en el ejército, los guaraníes se internaban en el monte, donde se subían a los árboles y cuando se cansaban caían al agua, de la cual salían escondidos bajo la forma de jaguares. El locutor quiso saber algo que yo también me había preguntado para mis adentros: si aquello había ocurrido realmente. En otra ocasión, al final de una charla que un guaraní había brindado ante una gran audiencia karai, me acerqué a

l Esta publicación, así como el trabajo de campo etnográfico que le da origen, fue financiada mediante una beca doctoral otorgada por el Consejo Nacional de Investigaciones y Técnicas (Conicet) de Argentina durante el período 2015-2019. Agradezco a todos los miembros de la comunidad Kuape Yayemboatì de Calilegua y su mburuvicha Marcelo Cuellar por compartir conmigo sus reflexiones e historias, entre ellas el mito de los mellizos analizado en este artículo.

2 En términos de los guaraníes, la aculturación es sinónimo de devenir karai (no indígena o blanco).

3 Residuo de la caña de azúcar que se utiliza en el proceso de producción de papel. Es causante de la enfermedad respiratoria conocida como bagasosis.

4 Inicialmente ingenio azucarero, la empresa Ledesma S.A.A.I. ha diversificado su producción (e incorporado papel, bioetanol, frutas). "Ledesma" también refiere el departamento de Jujuy donde se encuentra la empresa.

5 En este contexto, karai puede traducirse como no indígena, foráneo o blanco, por oposición a indígena o guaraní. 
preguntarle si aquellas historias que había contado sobre el origen del mundo eran, como él mismo las había calificado, "leyendas con lindas enseñanzas para los niños". Aclaré mi duda y repregunté: "¿los mitos son para ustedes historias verdaderas?" En efecto, la traducción de la categoría mitos (o leyendas) en términos de los guaraníes con quienes trabajo implica un despojo de la connotación de falsedad que, por oposición a la verdad histórica, se le ha atribuido.

Ya datan de varias décadas las críticas a las posturas antropológicas que sostuvieron que los indígenas de Sudamérica se encontraban fuera del tiempo y que eran sociedades sin historia. Gracias a los aportes de la etnohistoria, la antropología y la arqueología, se ha dado cuenta de los procesos de cambio y de la inadecuación de la rúbrica "pueblos sin historia". Desde numerosas etnografías contemporáneas se ha ahondado en las categorías nativas de tiempo, memoria, agencia histórica, cambio y transformación, entre otras (Gow 2001; Rumsey y Weiner 2001; Fausto y Heckenberger 2007; Tola y Suárez 2016). Muchas de estas investigaciones se han inspirado en los postulados levistraussianos acerca de la mitología amerindia; tal como sostiene Peter Gow (2001), hay en ella un profundo interés por entender la concepción histórica desde el punto de vista de los nativos.

El interés por repensar las categorías temporales e históricas en los términos de los propios indígenas podría vincularse a los postulados de ciertas vertientes del giro ontológico ${ }^{6}$ en antropología. En términos generales, desde una perspectiva ontológica, se parte de la base que, más que diversas visiones sobre un único mundo (perspectiva culturalista), existen una pluralidad de mundos posibles. Así, más que diversas interpretaciones históricas sobre sucesos pasados, estaríamos frente a otros pasados. Inclusive, sería pertinente preguntarse qué entienden los guaraníes, en este caso, por pasado. Como ya es bien sabido, no todas las historias posibles tienen el mismo valor frente a la historia dominante. ${ }^{7}$ Las historias de hombres que se transforman en jaguares y de gemelos míticos que pueblan el continente permanecen en la sombra, olvidadas por los procesos de imposición de un único tipo de historicidad válida.

En este trabajo me propongo reflexionar sobre el mito de los mellizos -ampliamente difundido en la mitología sudamericana - que registré entre los guaraníes de Jujuy y sobre sus aportes para la historia e historiografía del pueblo chiriguano (como son conocidos los guaraníes de esta región en la literatura etnohistórica y etnográfica). Lejos de una abstracción, este mito de origen implica un posicionamiento histórico y político frente a los discursos

6 En lo absoluto homogéneo, este giro aglutina mayormente a antropólogos y filósofos de diversas corrientes y tradiciones, que tienen por denominador común el interés por las ontologías, por el modo en que está compuesto un mundo, los existentes que lo pueblan y las relaciones que tejen entre sí, y el reconocimiento del pluralismo ontológico.

7 Utilizo el concepto de "historia dominante" o "historia hegemónica" no en referencia a la corriente historiográfica, sino a aquellas perspectivas que excluyen la mitología de la historia. 
que estigmatizan a los guaraníes de la región como "extranjeros" y ponen en tela de juicio su ancestralidad en el territorio. Tomar en serio (Castro 2002) la mitología indígena conduce ya no a interpretar dichas historias como evocaciones simbólicas ni a determinar la verdad o falsedad de las mismas y su coincidencia o no con la historiografía, sino que apunta al proyecto político de pluralizar la historia.

\section{ANTES Y AHORA: ADVENEDIZOS, EXTRANJEROS Y MESTIZOS}

Los guaraníes de la región son referidos, en las fuentes y en la literatura etnohistórica, como chiriguanos. En mi trabajo elijo el término guaraní que es con el que se auto-identifican mis interlocutores y solo utilizaré el etnónimo chiriguano al referirme a las corrientes historiográficas y etnográficas que así los denominan. Los guaraníes de Jujuy (NOA) forman parte de un pueblo amerindio de ascendencia tupí-guaraní, ${ }^{8}$ cuyo territorio corresponde a las estribaciones surorientales de los Andes en los confines occidentales del Gran Chaco. Los numerosos pueblos de la gran familia lingüístico-cultural tupí-guaraní se encuentran extendidos por vastas regiones del continente americano (en los países de Argentina, Bolivia, Brasil y Paraguay fundamentalmente).

Este apartado dedicado a la historiografía del pueblo chiriguano no pretende ser exhaustivo y tiene por objetivo contextualizar el problema de la ancestralidad/extranjería guaraní en esta región. Asimismo, pretende presentar aspectos de la historia de este pueblo para los que, en líneas generales, hay consenso entre historiadores y antropólogos. Sin embargo, dichos aspectos generan contradicciones si se coteja la perspectiva guaraní. Tal como sostiene el antropólogo y sociólogo guaraní Elías Caurey existen dos versiones ${ }^{9}$ en cuanto a la presencia guaraní en el piedemonte andino: por un lado, la que proviene desde la Asamblea Pueblo Guaraní (APG) ${ }^{10}$ y que sostiene la ancestralidad guaraní en dicho territorio y, por otro lado, la difundida versión karai o académica (Caurey 2015) en la que nos centraremos en este apartado.

\section{Los "advenedizos" de antes: los chiriguanos en el piedemonte}

Ya en el siglo XVI, el Virrey Toledo justificaba la guerra contra los chiriguanos, argumentando frente a la Corona Española: "son advenedizos, es decir, extranjeros, llegados de tierras del Río de La Plata" (citado en Pifarré 2015: 38). El padre dominico Lizárraga afirmaba lo mismo: "No son naturales sino advenedizos. Vinieron allí del Río de la Plata" (citado en Combès 201 1: 66).

8 Y como se verá, según la historiografía, también de ascendencia arawak.

9 Si bien esta división antagónica de versiones es postulada por mis interlocutores, es válido aclarar que no se trata de dos bloques homogéneos sin matices internos.

10 Organización creada en 1987 que nuclea a los guaraníes de Bolivia. También existe la APG de Mbaporenda. 
Al igual que Toledo y Lizárraga, todos los autores de la época, explicita la especialista del área Isabelle Combès, repetían lo mismo:

"los chiriguanaes no son originarios ni de la Cordillera que lleva su nombre, ni de la región de Chiquitos, llegaron allí desde un(os) punto(s) no precisados del "Río de la Plata" - expresión ésa que, en el siglo XVI, abarcaba no sólo la desembocadura del Paraná a la altura de Buenos Aires, sino todo su curso y el del río Paraguay" (201 1: 66).

La denominación "chiriguano" y su versión más temprana "chiriguanaes" hacen referencia a un conjunto de poblaciones de origen guaraní que ocupó, según la historiografía, las estribaciones surorientales de los Andes (Oliveto $2010)$ en fechas imprecisas antes de la conquista y a través de diversas oleadas migratorias (Pifarré 2015; Combès 201 1; Oliveto 2010). Vale aclarar que en las fuentes el término "chiriguana" es polisémico. Entre otras acepciones, fue usado para designar tanto la región del piedemonte andino como al grupo étnico que la habitó (Cruz 2017). En términos de los guaraníes actuales, la denominación "chiriguano" es peyorativa en tanto provendría de un nombre despectivo dado por los incas a los guaraníes capturados por aquellos. Sin embargo, dicho carácter despectivo del término es polemizado por el etnohistoriador Thierry Saignes, quien sostiene que el etnónimo proviene de una alteración del término guaraní de "chiriones", que tiene una connotación de mestizaje (Saignes 2007b). Xavier Albó (1990) considera en este sentido que, lejos de ser despectivo, el término da cuenta de la especificidad de un pueblo, diferenciado dentro de la gran familia guaraní. A la luz de la etnografía amerindia contemporánea, podría pensarse que el mestizaje, más que un rasgo particular chiriguano, es producto de una socio-lógica amerindia transformacional de relación con la alteridad. Tal como Gow (2003) reflexiona, el fenómeno "ex-cocama" (transformación de los indígenas "cocama" en "campesinos de sangre mezclada" en la Amazonía peruana) refleja dicha lógica amerindia de transformación de la alteridad en identidad. El énfasis en la etnogénesis mestiza de los chiriguanos pareciera pasar por alto la generalidad y extensión del mestizaje (tanto biológico como cultural, es decir, la incorporación de lo ajeno bajo distintas formas) en los mundos amerindios regidos por lógicas de "apertura al otro" (Lévi-Strauss 1992).

En términos de Alfred Métraux (1927), la migración se constituye como rasgo característico de los grupos de la familia lingüística tupí-guaraní. Más allá del tinte generalista del argumento (Julien 2007), es posible ver en las rutas prehispánicas que llevaron a los guaraníes desde el este hacia el piedemonte andino, esta tendencia a la movilidad. Motivados por múltiples causas que oscilan, según los autores, ${ }^{11}$ entre aquellas de índole religiosa y profética, como 
la búsqueda de la tierra sin mal, ${ }^{12}$ y otras de índole histórica, política, económica y/o ecológica, los guaraníes habrían llegado al piedemonte andino entre los siglos XIV y XVI aproximadamente. Según Métraux y Erland Nordenskiöld, estas migraciones habrían sido efecto de la llegada de los europeos (Bossert y Villar 2007). Bastante más lejos llegan los autores que sugieren, con base en cerámicas descubiertas por Marti Pärssinen y Ari Siiriäinen, que la presencia guaraní en la región podría remontarse al año 400 (Pifarré 2015).

Más allá de las imprecisiones cronológicas, el pueblo chiriguano no poseería - desde las crónicas tempranas y la historiografía - ancestralidad en el territorio que actualmente ocupa. Pueblo no solo sin territorio, sino que también sin identidad homogénea, según Saignes (2007a), se distingue en este punto del resto de los pueblos amerindios. Hay común acuerdo entre historiadores y antropólogos respecto del origen mestizo de los chiriguanos (Hirsch 2004b; Villar 2005; Saignes 2007a; Combès y Villar 2007; Oliveto 2010; Pifarré 2015), quienes habrían surgido de la mezcla que se produjo entre dos grupos amerindios: los chané (de origen arawak) y los guaraníes provenientes de Brasil y Paraguay. Los guaraníes, menos numerosos que los chané, habrían sometido a estos grupos de origen amazónico. Sin embargo, Diego Villar (2005) afirma que hubo tanta guarinización de los chané como arawakización de los guaraníes. Mientras que la cultura arawak aportó, según Villar (2005), la densidad demográfica, las mujeres y la fuerza masculina de trabajo, las técnicas de alfarería, riego y tejido, el enmascaramiento ritual y las jerarquías de estratificación social; la cultura guaraní aportó un gran número de motivos mitológicos y fundamentalmente el idioma.

Esta imagen de "migrantes mestizos" o "invasores amestizados" (Saignes 2007a) tiene vigencia en las miradas que se tiene sobre los actuales guaraníes de Jujuy. Dentro del área conocida en la etnohistoria como Chiriguanía o Cordillera Chiriguana - territorio guaraní desde la perspectiva de mis interlocutores - queda excluida la región del NOA que corresponde a la provincia de Jujuy: "La chiriguanía abarcó un espacio muy amplio que, como una medialuna, abrazó por el este los dominios coloniales desde la actual Cochabamba, pasando por Santa Cruz de la Sierra, en Bolivia, hasta Salta en Argentina" (Oliveto 2010: 46). La zona que interesa a mi trabajo, al sur del sector sur de la Chiriguanía, no correspondería según la historiografía a territorio guaraní. De todos modos, la ancestralidad tampoco les es concedida a los advenedizos "invasores mestizos" que llegaron en fechas inciertas, pero no inmemoriales al piedemonte.

12 Búsqueda profética, ampliamente difundida en la mitología y discursos políticos de grupos tupí-guaraní, de una tierra donde - a grandes rasgos - los cultivos crecen solos, la fiesta es eterna y no existe la muerte. 


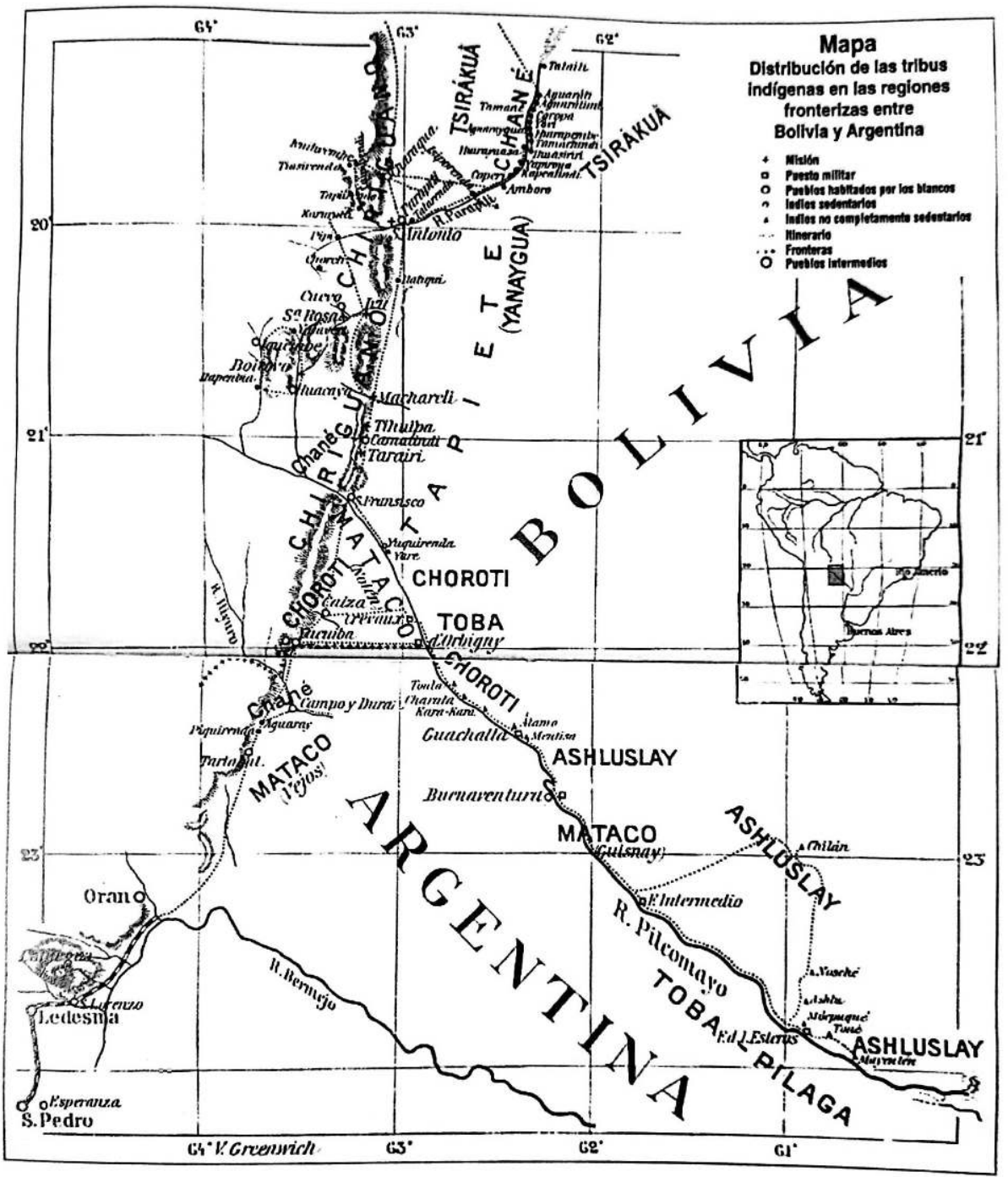

Figura 1 - Ubicación de los chiriguanos. Fuente: Nordenskiöld (1910).

\section{Los extranjeros de ahora: guaraníes en Jujuy}

Más allá que los guaraníes de Jujuy afirmen su preexistencia en la región, es cierto que la demografía guaraní en el NOA aumentó considerablemente debido a las masivas migraciones a Mbaporenda a fines del siglo XIX y principios del XX. Tal como consta en la historia oral, muchos parientes de los actuales guaraníes del NOA han migrado desde el país vecino de Bolivia escapando de la Guerra del Chaco y en búsqueda de mejores condiciones de trabajo en los ingenios azucareros en expansión en Salta y Jujuy (ambas provincias del NOA). Frente 


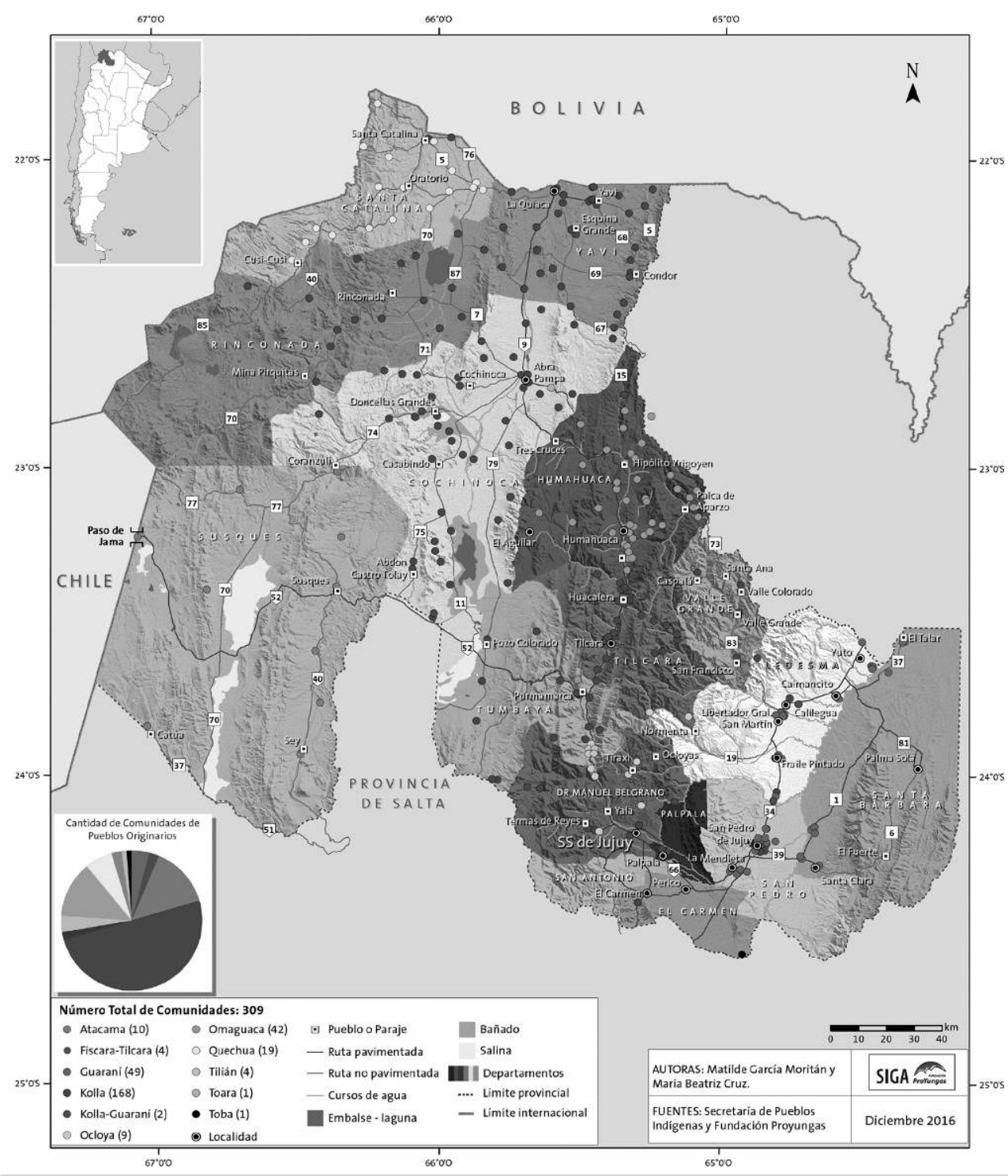

Figura 2 - Ubicación de comunidades guaraníes actuales. Fuente: Elaborado por Matilde García Moritán y María Beatríz Cruz.

al acorralamiento, despojo territorial, dependencia y explotación vivida en las haciendas y misiones de Bolivia, Mbaporenda se presentaba - paradójicamente dada la conocida historia de explotación vivida por los indígenas en los ingenios - como una "tierra con menos mal" adonde migrar (Hirsch 2004a).

En consonancia con el proceso de acorralamiento territorial de los guaraníes en Bolivia, se produjo en Argentina un auge económico: el boom azucarero. De las antiguas haciendas azucareras surgieron los modernos ingenios azu- 
careros favorecidos por las políticas proteccionistas, la progresiva llegada del ferrocarril y los subsidios estatales (Bossert 2012). A medida que aumentó la producción, indígenas del Gran Chaco (tobas, pilagás, mocovíes, wichís, nivaclés, guaraníes/chiriguanos) y de regiones andinas de Argentina y Bolivia fueron reclutados para trabajar forzosamente en la zafra, en condiciones indignas y precarizadas. Numerosos autores han destacado el carácter multiétnico inédito atravesado por diversos grupos en el escenario de los ingenios azucareros (Montani 2015).

Actualmente, en esta multiétnica y subtropical región, a orillas de la ruta número 34, muchas comunidades guaraníes y colla-guaraníes viven "entreveradas" en ciudades y pueblos de los departamentos jujeños de Ledesma, Santa Bárbara y San Pedro, restringidas a barrios y predios comunitarios. La comunidad Kuape Yayemboatł̇, donde realicé mi trabajo de campo, está ubicada a dos kilómetros de la ciudad de Libertador Gral. San Martín donde se encuentra el ingenio Ledesma, epicentro de la empresa homónima, principal fuente de trabajo de la región, propietaria casi excluyente del territorio del departamento y asociada no solo a explotación laboral y represión, sino a crímenes de lesa humanidad durante la última dictadura militar del país (Karasik y Gómez 2015).

A pesar de lo referido por las fuentes, mis interlocutores declaran: "nosotros estábamos acá antes" pero, por razones de discriminación y silenciamiento, no enfatizaban su adscripción étnica. Este silenciamiento es reproducido tanto entre indígenas como entre no indígenas que desconocen o deslegitiman las más de 50 comunidades guaraníes que conviven junto con ellos en la región. Fue desde los años 90 que los guaraníes del NOA comenzaron un proceso de "reemergencia" 13 y visibilización. En tiempos de globalización de la cuestión indígena y en el marco del Consejo Continental de la Nación Guaraní (CCNAGUA), ${ }^{14}$ los guaraníes con quienes trabajo se piensan como un pueblo panamericano que en un tiempo primordial se expandió por vastas regiones del continente dando origen a los diferentes pueblos tupí-guaraní. Las historias míticas de expansión y llegada a la región del NOA implican un posicionamiento (cosmo)político ${ }^{15}$ de los guaraníes frente a los discursos que los estigmatizan como indios truchos ${ }^{16}$ mestizos, chiriguanos, chaguancos ${ }^{17}$ y extranjeros.

13 En los últimos años, diversos autores han utilizado la categoría "reemergencia" en sentido amplio para hacer referencia a pueblos indígenas que habían sido declarados mediante dispositivos hegemónicos "extintos" - o "en extinción" - y que actualmente participan y manifiestan su presencia en el espacio público (Rodríguez 2017).

14 El Consejo Continental de la Nación Guaraní es una organización que engloba a los guaraníes de Argentina, Bolivia, Paraguay y Brasil.

15 La categoría cosmopolítica permite pensar más allá de la política, agenciada no solo por humanos.

16 Trucho hace referencia a poco auténtico, falso o ilegítimo.

17 Los guaraníes del NOA son también llamados despectivamente "chaguancos", nombre de origen quechua surgido en los ingenios que podría significar "piernas flacas”. 
EL MITO DE LOS MELLIZOS Y SUS IMPLICANCIAS HISTÓRICO-POLÍTICAS

\section{Del mito de los mellizos a la "hermandad" indígena en el devenir histórico global}

En el año 1932, Métraux pronosticaba la desaparición de los mitos indígenas chiriguanos en las generaciones venideras: "Mi colección de mitos y cuentos ha sido hecha in extremis y estoy persuadido que, dentro de pocos años, cuando los ancianos que hoy en día tienen más de 70 años hayan desaparecido, no quedará de aquellos ni el menor recuerdo" (1932: 119). En el siguiente párrafo, Métraux cita las palabras de un anciano ava-guaraní en las que el desinterés de las generaciones jóvenes por los mitos de su pueblo se relaciona con las migraciones a Argentina, lugar donde los indígenas se vuelven karai: "Como quieres que los Ava (los hombres por excelencia, es decir los Chiriguano) conozcan estas cosas, pues van a la Argentina, llevan zapatos y se parecen a los karai (blancos o mestizos)" (1932: 119). Sin embargo, casi un siglo después de su sentencia pesimista, en el "aculturado" y contaminado contexto de Ledesma, he tenido la oportunidad de escuchar varias versiones del mito de los mellizos emparentado por varios de sus elementos a aquellos recopilados por el antropólogo suizo-argentino.

Muchos de mis interlocutores han oído el mito en cuestión, aunque no puedan contarlo completo. En diversas reuniones, por iniciativa del mburuvicha ("líder") de la comunidad guaraní Kuape Yayemboatt, el mito de los mellizos fue objeto de caluroso debate. La versión que tomo en este apartado ha sido compartida por el mburuvicha en una asamblea a la que asistí. Luego de transcribirla, se la pasé por escrito y él realizó algunas modificaciones al texto original dando por resultado la versión de la que extraigo el siguiente fragmento y que elijo por sobre las demás, no por ser la más completa, sino porque en ella se ven claramente sus implicancias histórico-políticas:

"Cuentan que el pueblo guaraní venía por la época [...] antes de la evangelización, por el Amazonas, cerca del Mato Grosso, venían un grupo de hermanos que se cree que venían por ahí [...]. El pueblo guaraní era prácticamente como nómada, ¿no? Buscaban la tierra sin mal. fvì Maraet le dicen. tvè Maraét significa la tierra sin mal, la tierra fértil, la tierra donde hay el agua dulce, donde están los animalitos, donde todos pueden encontrar la miel. Todo eso, ¿no? Yo lo comparo eso con la historia de Moisés, no sé si ustedes recuerdan. Es parecido, ¿no? Del pueblo guaraní se cree [...] han encontrado rastros de ellos incluso en Venezuela. [...] Hasta se encontró rastro en América Central. Eso se contaba justamente dentro del CCNAGUA, que justamente fuimos nosotros a la reunión. Contaba una gente de ahí que se encontraban guaraníes en Centro América, por Venezuela, cerca de 
Brasil [...]. Bueno llegaron creo que hasta Brasil antes de la evangelización, en la época antes de la evangelización. Hay una historia ahí que dice que son dos mellicitos, dos gemelos, que se separan en un lugar, se dividen por tal causa. Había sido que Nandesi, había sido a través de dos dioses que la habían hecho embarazar: Tüpa Aguara y Tatu Tüpa. De ahí nacen. Y de ahí se cree que esos dos gemelitos representan al pueblo guaraní. Por eso dicen que llegan por Mato Grosso y ahí dicen que se separan estos pueblos. Uno para el norte, otro para el este y otro para el sur [...]. El pueblo guaraní, en ese Mato Grosso, que nosotros después llamamos Matł Moröcho o Mantiguoroso en idioma, se separan ellos en Mato Grosso. Van para Brasil, otros para Paraguay, otros para Bolivia y algunas partes de la Argentina. Y por eso es que ahora tenemos al pueblo guaraní en todos lados, un poco en Brasil, en Amazonas, en Paraguay, está en Uruguay, está en Bolivia, en parte de Argentina. Como el pueblo da esa idea que se encontraron muchos guaraníes por esa zona, se formó el CCNAGUA. Pero nosotros como no somos ni de Paraguay, ni de Bolivia, ni de ninguna de esas partes. Por ahí los gobiernos ponen en algún momento 'no, ustedes son de Bolivia', a la gente de Bolivia le dicen 'ustedes son de Paraguay', y a los que son de Paraguay les dicen 'no, ustedes son de Brasil', y sucesivamente, por cuestiones políticas, excusas por si ellos vayan a reclamar por tierra o desalojo, como una excusa por parte del gobierno. Acá nosotros tuvimos una época que le dijeron a los mburuvichas que nosotros no éramos de aquí, que éramos de Bolivia. Pero nosotros estábamos acá antes".

En primer lugar, sale a la luz en el relato el hilo histórico-político que conduce desde el tiempo mítico de creación del mundo por las deidades Tüpa Aguara (Dios Zorro) y Tatu Tüpa (Dios Armadillo) hacia la historia reciente de constitución del CCNAGUA y de lucha por un territorio que les fue quitado, no solo de hecho sino de derecho acusándolos de extranjeros. La unidad política actual del pueblo guaraní está fundada, como se ve, en un hecho del pasado remoto ubicado antes de la evangelización, es decir, antes de la llegada del blanco, en un tiempo que, como me cuentan, "la tierra era cuadrada". Mito, historia y política se hayan profundamente imbricados en este relato, razón por la cual resulta pertinente un abordaje que articule dichas dimensiones. Además de referir a la unidad política, el mito fundamenta la ancestralidad guaraní en el territorio americano, argumento que lleva a pensar más allá de la política (De la Cadena 2009) en términos cosmopolíticos (Stengers 2014). Mientras que el modo nativo de articular sin inconvenientes mito, historia y política da cuenta del potencial histórico del mito; la constatación de la extensión del mito y de la figura de los mellizos por vastas regiones de América lleva al terreno de lo impensable: que realmente haya ocurrido así, como sostienen los guaraníes con quienes trabajo. Esto último se fundamenta en reflexiones 
compartidas con mis interlocutores, para quienes la extensión del mito probaría su verdad histórica, transmitida de generación en generación.

Los mellizos míticos son los personajes más populares de la mitología sudamericana. Nunca idénticos, se presentan como opuestos y asociados a orientaciones, cualidades o intenciones contrarias. Como intentó demostrar Lévi-Strauss (1992) en Historia del Lince, la extensión de este mito permite pensar en un fondo común de pensamiento amerindio, ligado a una imposible gemelidad - de la cual deriva su tesis del dualismo en desequilibrio perpetuo y a una consecuente disposición del espíritu amerindio: la apertura al otro (Lévi-Strauss 1992; Souza y Fausto 2004; Chaumeil 2010). Asimismo, el mito está relacionado a una forma de concebir la historia propia de los amerindios, que muchas veces fue, como sostienen diversos autores (Gow 2001; Fausto y Heckenberger 2007), malinterpretada. Peter Gow (2001) considera que en el análisis de la mitología levistraussiana hay un profundo interés por entender la concepción histórica desde el punto de vista de los nativos. Según Lévi-Strauss, los mitos son objetos históricos que obliteran el paso del tiempo mediante sucesivas transformaciones. Este procedimiento nos enfrenta a otra noción de cambio y de transformación y difiere del objeto de la disciplina historia, es decir la historia de expansión y colonización que unifica a toda la humanidad.

Dando por hecho que todas las sociedades tienen historia y están en ella, la diferencia en términos levistraussianos radicaría en los diversos regímenes de historicidad que opondrían las sociedades frías (aquellas clásicas que estudia el antropólogo, mal llamadas "primitivas") a sociedades calientes como la nuestra ${ }^{18}$ (Lévi-Strauss 1971, 1997). Tal como sostiene en sus ya famosas aseveraciones, mientras las primeras "se bañan en un fluido histórico al cual se esfuerzan por permanecer impermeables", las segundas "interiorizan la historia para convertirla en el motor de su desarrollo” (Lévi-Strauss 1971: 34). Sin proclamar que se trate de un mecanismo frío que oblitera el paso del tiempo, puede pensarse la transformación del mito de los mellizos en Jujuy como efecto de la lógica mítica que actualiza el relato en el contexto de globalización de la cuestión indígena y de proliferación de discursos sobre una hermandad panamericana. ${ }^{19} \mathrm{Al}$ respecto, un elemento novedoso que aparece en los mitos de los guaraníes de Jujuy es la inclusión de otros pueblos amerindios de la familia tupí-guaraní. Si bien en el relato transcripto ambos gemelos pertenecen al pueblo guaraní, en otras versiones que registré uno de los gemelos (llamado Tupí) es el ancestro originario de los tupí.

18 Esta división ha generado fuertes debates sobre la historia e historicidad indígena.

19 Pese a la centralidad del cuñadío en sociedades amerindias (Souza y Fausto 2004), actualmente entre los guaraníes del piedemonte la hermandad adquiere fundamental relevancia. Más allá de la existencia o ausencia de consanguinidad, todo guaraní llama a otro guaraní "hermano", inclusive en algunos casos la hermandad es extendida a otros grupos indígenas. 
¿Puede esta apertura al otro indígena, considerado hermano, pero nunca idéntico, expresar cierta gemelidad imposible - o, mejor dicho, hermandad imposible - en el contexto político actual de unidad de los pueblos indígenas? Sobre la constitución de la APG, que nuclea al pueblo guaraní de Bolivia, Bartomeu Meliá la ha calificado como un hito histórico al constatar que, por primera vez en la historia, este pueblo libre y sin dueño había constituido una organización unitaria (Albó 2007). Más llamativa aún resulta la conformación del CCNAGUA que nuclea al pueblo guaraní en su conjunto. Sin embargo, siguiendo el planteo de Lévi-Strauss, es pertinente recordar que toda unidad puede reafirmar una dualidad (1992: 104). Volviendo a sus implicancias histórico-políticas, el relato mítico que se abre a los pueblos tupí y a todos los guaraníes extendidos por el continente pareciera anticipar en su estructura, desde tiempos inmemoriales, la globalización y hermandad indígena actual. Así como el lugar del "blanco" estaba marcado, mucho antes del "descubrimiento" de América, en el sistema de pensamiento amerindio (Lévi-Strauss 1992; Chaumeil 2010), los otros grupos indígenas también tenían su lugar en las dicotomías mitológicas.

\section{Hacia los impensables mitológicos: otros mundos, otro pasado}

El mito de los mellizos difiere de la historia hegemónica no solo por la noción de transformación que implica, sino por su contenido que expresa otro posible pasado, aunque éste se presente como impensable. Tal como sostiene Michel-Rolph Troulliot (1995), lo impensable es aquello que es inconcebible en tanto pervierte todas las respuestas porque desafía los términos bajo los cuales se pueden plantear las preguntas. Según Mario Blaser y Marisol de la Cadena (2009), lo hegemónicamente impensable en la actualidad no es que los indígenas hagan política - esto ya está aceptado desde el sentido común -; lo impensable son los modos y términos conceptuales de esa praxis política que implican un ensanchamiento ontológico de los agentes que participan en ella.

Siguiendo estos lineamientos, lo impensable no es que los pueblos indígenas tengan y estén en la historia, sino más bien aquellos modos de hacer y concebir los hechos del pasado o los pasados otros. El mito de los mellizos no solo cuestiona la historia hegemónica por expresar otro modo de concebir el paso del tiempo, el cambio y la transformación. Por su contenido, este mito expone otro pasado y un territorio compuesto por mundos sociales no-humanos. Dada la extensión que posee en el continente, este mito refuerza la posibilidad de pensar en una realidad pretérita filtrada por las ontologías indígenas. Es así que tomar en serio el mito permite adentrarse en el terreno de lo impensable por dos vías: por su contenido y por su extensión.

La figura de los mellizos, popularizada en el ámbito académico por Métraux (1932), se encuentra ampliamente difundida en la mitología amerindia (Hirtzel 2012; Chaumeil 2010). Omnipresente en la región sudamericana, 
este mito es relatado por diversos grupos amazónicos, chaqueños e inclusive andinos. Particularmente notable es su distribución dentro de los subgrupos de la amplia familia lingüística tupí-guaraní. Esquemáticamente, las infinitas versiones registradas entre varios pueblos indígenas cuentan la siguiente historia: una mujer primigenia, embarazada (generalmente de mellizos) se pierde y llega a la morada de los jaguares donde es acogida amablemente y protegida de los temibles felinos por un personaje descripto como la madre o abuela de los jaguares. Los felinos matan a la mujer y extraen de su vientre a sus hijos quienes crecen en el mundo de los jaguares y, al descubrir que su madre ha sido asesinada, deciden vengarse. Ciertos elementos, como el episodio de venganza o la vida imposible con los jaguares, se repiten en las diversas versiones (Hirtzel 2012).

La visita a la casa de los jaguares no se encuentra presente en el relato transcripto en el apartado anterior, pero el mismo narrador me refirió acerca de ella en otra ocasión y también aparece en una versión escrita que, lejos del contexto "ideal" de transmisión de relatos míticos, me envió vía Facebook. En ella, luego de la creación del mundo y de la primera mujer Nandesi por obra de los dioses Tüpa Aguara y Tatu Tüpa, ambas deidades tuvieron relaciones sexuales con ella y, enojadas por la infidelidad, la abandonaron embarazada en la selva recientemente creada:

"Ella, con los gemelos, vagó por la selva pero se perdió y llegó al país de los jaguares. La abuela de los felinos quiso esconderla; las fieras sin embargo la olfatearon y devoraron. El constructor y su compañero, arrepentidos, solo pudieron desde los cielos salvar a sus dos hijos. Los gemelos fueron criados por la abuela de los jaguares. Crecieron pronto y se hicieron infalibles cazadores. Algunas aves, antes de morir, pudieron contarles su historia y los hermanos decidieron vengar a su madre. Dijeron entonces a los jaguares que en sus andanzas por la selva habían descubierto una tierra paradisíaca donde los alimentos abundaban y se recogían sin esfuerzo. Allá no se conocía el mal, les aseguraron. Pero para alcanzarla era necesario llegar hasta el confín de la tierra, donde nace el día para encontrarse con el mar, cruzarlo y ganar la felicidad. Los jaguares les creyeron y se embarcaron en grandes canoas que los gemelos habían hecho. Pero los gemelos, que por herencia de sus padres dominaban los elementos desencadenaron una terrible tempestad como venganza. Las canoas naufragaron y los jaguares fueron convertidos en toda clase de animales. Fue así que entonces los gemelos decidieron repoblar la tierra".

La visita al mundo de los jaguares se corresponde con la existencia de múltiples mundos sociales no-humanos, tantos como dueños (iya reta) existen. En el mundo guaraní en general, y en otros grupos guaraní hablantes como los 
chané ${ }^{20}$ todas las cosas son poseídas, administradas y reguladas por múltiples entidades denominadas iya reta (Villar 2005). Este universo superpoblado de iya reta contrasta con el carácter iyambae, es decir, sin dueño, que proclaman mis interlocutores para sí mismos y para el pueblo guaraní en su conjunto. Por lo demás, emociones, objetos, seres y elementos del entorno (como el agua, los ríos, peces, el jaguareté, los pájaros), fiestas (la principal fiesta guaraní, el arete guasu), instrumentos musicales, grupos étnicos, entre tantas cosas, tienen sus respectivos dueños. Cada uno de los iya reta pertenece a un mundo social no-humano: así existen el mundo de los jaguares, el mundo acuático de la dueña de los peces, el mundo regido por el dueño del palo borracho, entre otros.

Uno de estos tantos otros mundos es el Matł Moröcho (traducido por mis interlocutores como Mato Grosso), ubicado en un lugar en el medio de la selva, donde están los antepasados a quienes gustaba mucho el arete guasu. ${ }^{21}$ La asimilación del Mantiguoroso ${ }^{22}$ al Mato Grosso entre grupos guaranizados del Isoso (Bolivia) ha sido subrayada por Combès (2005), quien realizó un profundo análisis etnohistórico al respecto en el cual se observa su vinculación con la morada de los antepasados. Se puede suponer que los guaraníes no se refieran al Mato Grosso como el estado de Brasil sino que ubiquen este mundo social no-humano en las profundidades de la selva, dado que el portugués "mato grosso" se traduce al español como "selva espesa". Por otro lado, su ubicación mediterránea - en el centro-oeste de Brasil y aproximadamente en el centro del continente - remite al origen mítico del pueblo. A pesar de situar su ubicación geográfica, según los guaraníes no es posible acceder allí por vías terrenales ya que Matł Moröcho se encuentra en una dimensión no-humana. La temporalidad guaraní se encuentra así íntimamente ligada a una geografía cosmológica que se superpone al mapa físico-político del continente.

"El pasado está en el futuro" es una expresión frecuente de los guaraníes que remite a la extensa caminata de este pueblo en búsqueda de la tierra sin mal. Entre los guaraníes del piedemonte, esto implica una espacialización del tiempo en tanto el "futuro" hace referencia al "lugar donde están los antepasados" (Matł Moröcho). La confluencia del futuro con el pasado también se explica por el punto de origen del pueblo guaraní. ${ }^{23} \mathrm{Su}$ historia comienza

20 La noción de "dueño" se encuentra ampliamente difundida y resulta central en las sociedades indígenas de tierras bajas sudamericanas, tal como se observa en la etnografía americanista (Fausto 2008). 21 Como me cuentan los guaraníes, las personas, al morir, se dirigen a uno de estos mundos no-humanos, al cual, por preferencia y gusto, se sienten atraídos.

22 Según Combès (2006), Matiguoroso es una palabra enigmática que puede traducirse como la expresión "venimos de lejos" o como "Mato Grosso". Mis interlocutores escriben principalmente "Matí Moröcho" y lo traducen como "Mato Grosso".

23 Combès (2006) señala esta confluencia en la cual el punto de origen (pasado mítico) es al mismo tiempo destino humano (futuro). 
en medio del continente donde no solo se encuentran actualmente los antepasados, sino que es desde donde se han dispersado los hermanos míticos repoblando la tierra y dando lugar a todos los pueblos de la gran familia tupí-guaraní. El pasado mítico se anuda al futuro en este punto del continente, espacializando de este modo la temporalidad y obliterando el paso del tiempo. Pasado y futuro están ubicados ambos en el Matł Moröcho: desde allí una línea empezó a dibujar la gran caminata guaraní ramificándose por el continente. El presente puede entenderse como múltiples líneas en movimiento que retornarán en el futuro a su punto de origen, es decir, al pasado.

\section{CONSIDERACIONES FINALES:}

\section{EL PASADO EN DISPUTA Y LOS CONFLICTOS "ONTOHISTÓRICOS”}

En este trabajo, interesada por la historia en términos nativos y partiendo de mi etnografía, tomé el mito de los mellizos como objeto histórico que cuestiona la historia dominante por su modo de concebir el paso del tiempo y por su contenido que remite a un pasado impensable. Asimismo, el mito se enfrenta a la historiografía de la región: si desde ésta, la ocupación guaraní de las estribaciones surorientales de los Andes ocurre en un tiempo posterior al poblamiento del continente, en fechas previas a la conquista, desde la perspectiva nativa es el mito que explica dicho poblamiento y ocupación. Siguiendo los lineamientos de perspectivas antropológicas que buscan nuevos objetos históricos distintos al de la historia como disciplina, me propuse partir de las fuentes secundarias - producto de la etnografía - en lugar de comenzar por los documentos de archivo (Gow 2001). En un sentido similar, Carlos Fausto y Michael Heckenberger (2007) sostienen que para evitar proyectar nuestras propias nociones de historia en las sociedades amerindias es necesario teñir la historiografía con la mirada etnográfica.

La confrontación del mito de los mellizos con la historia del pueblo chiriguano que reconstruye la historiografía genera cortocircuitos que hacen que ambas perspectivas del pasado sean incompatibles. Sin embargo, determinar la verdad o falsedad de las historias otras o la coincidencia o no con la historiografía no es el objetivo del presente trabajo. Me propuse, más precisamente, echar luz sobre el conflicto ontológico (Blaser 2009) de orden histórico que se presenta si se intenta sostener en simultáneo la ancestralidad mítica de un pueblo (a partir del mito de los mellizos) y la foraneidad del mismo (siguiendo a la historiografía). La inconmensurabilidad de los relatos refiere sin duda a los distintos filtros ontológicos que influyen en los abordajes históricos, dando por resultado en este caso al menos dos pasados contrapuestos. La importancia de considerar las ontologías en los abordajes históricos ya fue remarcada por Florencia Tola al proponer el concepto de "ontohistorias" para abordar la forma indígena de los qom o tobas de referir a los hechos del pasado (Tola 
y Suárez 2016). Retomando este concepto, el cortocircuito que salta a la luz entre el pasado mítico y el pasado historiográfico podría pensarse como un conflicto "ontohistórico".

En un ejercicio de simetrizar la historia se pueden tomar dos caminos con el fin de equiparar el status epistemológico de las versiones contrapuestas. Una de las opciones sería cuestionar la objetividad de la historiografía y acercarla al ámbito del mito admitiendo que todos somos nativos. La segunda opción sería seguir la propuesta de la antropología simétrica y admitir que somos todos antropólogos en igual medida, pero de modos diferentes (Castro 2002). Ahora bien, siguiendo a Viveiros de Castro, el discurso antropológico (o historiográfico, en este caso) tiene ventajas epistemológicas por sobre el discurso nativo: el primero da forma - en tanto explica, traduce, textualiza y contextualiza - al segundo que proporciona la materia. En un ejercicio de antropología simétrica, se podría intentar rechazar esta ventaja para pensar en qué medida la forma intrínseca de la materia del discurso nativo modifica la materia implícita de la forma del discurso antropológico (Castro 2002). ¿Podría la estructura intrínseca del mito de los mellizos dar forma y traducir al discurso historiográfico? ¿Podría la hermandad mítica de los pueblos tupí-guaraní explicar y contextualizar la formación de una organización continental como el CCNAGUA?

Para ello, el primer paso sería tomar en serio las historicidades indígenas, es decir, dejar de verlas como concepciones para comprenderlas como verdaderos conceptos filosóficos que constituyen mundos, historias y pasados posibles. La espacialidad cosmológica y linealidad histórica guaraníes - como líneas múltiples, siempre en movimiento y retornando al origen - pueden ser tan sugestivas como, por ejemplo, la dialéctica de la memoria de Walter Benjamin. La propuesta de pluralizar la historia implica no solo multiplicar los conceptos, sino que también se relaciona con ensanchar los agentes que, como los gemelos míticos, jaguares y dioses hacen la historia.

Es indiscutible el valor político de una perspectiva ontológica que busque multiplicar los mundos, las voces y las historias: diferir y multiplicar es un acto político por derecho propio. Sin embargo, introducir lo impensable en los discursos aceptados puede tener efectos políticos - tal como se entiende la política en nuestros términos - en el marco de las luchas territoriales indígenas. Los relatos míticos, entendidos como verdades históricas nativas, pueden constituirse como legítimas herramientas de lucha para argumentar, por ejemplo, la ancestralidad guaraní en el piedemonte andino. La inclusión de la mitología en la historia apunta, así, al proyecto político de pluralizar la historia. 


\section{BIBLIOGRAFÍA}

ALBÓ, Xavier, 1990, Los Guaraní-Chiriguanos III: la Comunidad Hoy. La Paz, CIPCA.

ALBÓ, Xavier, 2007, "Prólogo", en Isabelle Combès (comp.), Historia del Pueblo Chiriguano.

La Paz, Plural Editores, 9-16.

BLASER, Mario, 2009, "La ontología política de un programa de caza sustentable”, Red de Antropologías del Mundo - World Anthropologies Network (WAN-RAM), 4: 81-107.

BLASER, Mario, y Marisol DE LA CADENA, 2009, "Introducción”, Red de Antropologías del Mundo - World Anthropologies Network (WAN-RAM), 4: 1-9.

BOSSERT, Federico, 2012, "Notas sobre la jerarquía interétnica en los ingenios azucareros del Noroeste Argentino", en Isabelle Combès y Diego Villar (comps.), Las Tierras Bajas de Bolivia: Miradas Históricas y Antropológicas. Santa Cruz de la Sierra, Editorial El País, 217-237.

BOSSERT, Federico, y Diego VILLAR, 2007, "La etnología chiriguano de Alfred Métraux", Journal de la Société des Américanistes, 93 (1): 127-166.

CASTRO, Eduardo Viveiros de, 2002, “O nativo relativo”, Mana, 8 (1): 113-148.

CASTRO, Eduardo Viveiros de, 2004, "Perspectival anthropology and the method of controlled equivocation”, Tipití, 2 (1): 3-22.

CAUrey, Elías, 2015, Asamblea del Pueblo Guaraní: Un Breve Repaso a Su Historia. S.1., Territorio Guaraní - Bolívia.

CHAUMEIL, Jean-Pierre, 2010, "Historia de Lince, de Inca y de Blanco: la percepción del cambio social en las tradiciones amerindias”, Maguaré, 24: 59-67.

COMBÈS, Isabelle, 2005, Etno-Historias del Isoso: Chané y Chiriguanos del Chaco Boliviano (Siglos XVI al XX). La Paz, IFEA/PIEB.

COMBÈS, Isabelle, 2006, "De los candires a Kandire: la invención de un mito chiriguano", Journal de la Société des Américanistes, 92 (1-2): 137-163.

COMBÈS, Isabelle, 2011, "El Paititi y las migraciones guaraníes", en Isabelle Combès (comp.), Paititi: Ensayos y Documentos. Cochabamba, Editorial Itinerarios, 52-98.

COMBÈS, Isabelle, y Diego VILLAR, 2007, “Os mestiços mais puros: representações chiriguano e chané da mestiçagem”, Mana, 13 (1): 41-62.

CRUZ, Pablo, 2017, "Memorias de montañas y metales: incas y chiriguanaes en el este de los Andes”, en Beatriz Ventura, Gabriela Ortíz y María B. Cremonte, Arqueología de la Vertiente Oriental Surandina: Interacción Macro-Regional, Materialidades, Economía y Ritualidad. Buenos Aires, Sociedad Argentina de Antropología, 205-235.

DE LA CADENA, Marisol, 2009, "Política indígena: Un análisis más allá de la política", Red de Antropologías del Mundo - World Anthropologies Network (WAN-RAM) 4: 189-171.

FAUSTO, Carlos, 2008, "Donos demais: maestria e propriedade na Amazônia", Mana, 14: 329-366.

FAUSTO, Carlos, y Michael HECKENBERGER (comps.), 2007, Time and Memory in Indigenous Amazonia: Anthropological Perspectives. Gainesville, FL, University Press of Florida.

GOW, Peter, 2001, An Amazonian Myth and Its History. Oxford, Oxford University Press.

GOW, Peter, 2003, “Ex-Cocama’: identidades em transformação na Amazônia peruana”, Mana, 9 (1): 57-79.

HIRSCH, Silvia, 2004a, "Mbaporenda: el lugar donde hay trabajo: Migraciones guaraníes al noroeste argentino", disponible en < https:/etnohistoria.equiponaya.com.ar/htm/04_art iculo.htm $>$ (última consulta en junio de 2020). 
HIRSCH, Silvia, 2004b, "Ser Guaraní en el Noroeste Argentino: variaciones de la construcción identitaria”, Revista de Indias, 14 (230): 67-80.

HIRTZEL, Vincent, 2012, "La historia de un mito antes de la 'historia': acerca de algunas versiones yuracaré y chiriguana del mito de los mellizos", en François Correa Rubio, Jean-Pierre Chaumeil y Roberto Pineda Camacho (comps.), El Aliento de la Memoria: Antropología e Historia en la Amazonia Indígena. Bogotá, Universidad Nacional de Colombia, 89-120.

JULIEN, Catherine, 2007, "Kandire in real time and space: sixteenth-century expeditions from the Pantanal to the Andes", Ethnohistory, 54 (2): 245-272.

KARASIK, Gabriela, y Elizabeth GÓMEZ, 2015, "La empresa Ledesma y la represión en la década del 70: conocimiento, verdad jurídica y poder en los juicios de lesa humanidad", Clepsidra: Revista Interdisciplinaria de Estudios sobre Memoria, 3: 110-131.

LÉVI-STRAUSS, Claude, 1971, Entrevistas de Georges Charbonnier con Claude Lévi-Strauss. México, DF, Siglo XXI Editores.

LÉVI-STRAUSS, Claude, 1992, Historia del Lince. Barcelona, Editorial Anagrama.

LÉVI-STrAusS, Claude, 1997, El Pensamiento Salvaje. México, DF, Fondo de Cultura Económica.

MELIÁ, Bartomeu, 1995, "La tierra sin mal de los Guarani: economia y profecía”, en Jürgen Riester (comp.), Chiriguano. Santa Cruz, APCOB.

MÉTRAUX, Alfred, 1927, "Les migrations historiques des Tupí-Guaraní", Journal de la Société des Americanistes, 19: 1-45.

MÉTRAUX, Alfred, 1932, "Mitos y cuentos de los indios chiriguano", Revista del Museo de La Plata, 33: 119-184.

MONTANI, Rodrigo, 2015, "El ingenio como superartefacto: notas para una etnografía histórica de la cultura material wichí”, en Lorena Córdoba, Federico Bossert y Nicolas Richard (comps.), Capitalismo en las Selvas: Enclaves Industriales en el Chaco y Amazonia Indígenas (1850-1950), San Pedro de Atacama, Ediciones del Desierto, 19-44.

NORDENSKIÖLD, Erland, 1910, Indianlif i El Gran Chaco (Syd-Amerika). Estocolmo, Albert Bonniers Förlag.

OLIVETO, Guillermina, 2010, “Chiriguanos: la construcción de un estereotipo en la política colonizadora del sur andino", Memoria Americana, 18 (1): 43-69.

PIFARRÉ, Francisco, 2015, Historia de Un Pueblo: los Guaraní-Chiriguano. La Paz, Fundación Xavier Albó.

RODRÍGUEZ, Mariela Eva, 2017, "Reemergencia indígena en los países del Plata: los casos de Uruguay y de Argentina”, Conversaciones del Cono Sur, 3 (1): 2-8.

RUMSEY, Alan, y James WEINER, 2001, Emplaced Myth: Space, Narrative, and Knowledge in Aboriginal Australia and Papua New Guinea. Honolulu, University of Hawaii Press.

SAIGNES, Thierry, 2007a, "El malentendido inacabado", en Isabelle Combès (comp.), Historia del Pueblo Chiriguano. La Paz, Plural Editores, 31-38.

SAIGNES, Thierry, 2007b, "Guerra e identidad", en Isabelle Combès (comp.), Historia del Pueblo Chiriguano. La Paz, Plural Editores, 69-96.

SOUZA, Marcela Coelho de, y Carlos FAUSTO, 2004, "Reconquistando o campo perdido: o que Lévi-Strauss deve aos ameríndios”, Revista de Antropologia, 47 (1): 89-131.

STENGERS, Isabelle, 2014, "La propuesta cosmopolítica", Pléyade, 14: 17-41.

TOLA, Florencia, y Valentín SUAREZ, 2016, El Teatro Chaqueño de las Crueldades: Memorias Qom de la Violencia y el Poder. Buenos Aires, Rumbo Sur/Ethnographica. 
TrOulliot, Michel-Rolph, 1995, Silencing the Past: Power and the Production of History. Boston, Beacon Press.

VILLAR, Diego, 2005, La Religión Chané. Buenos Aires, FFyL-UBA, tesis de doctorado.

Receção da versão original / Original version

Aceitação / Accepted
$2018 / 05 / 15$

$2019 / 11 / 18$ 